Revista Iberoamericana, Vol. LXXX, Núm. 246, Enero-Marzo 2014, 49-65

\title{
DEL DISCURSO METAHISTÓRICO A LA PARODIA DEL RELATO MÍTICO: GÉNESIS DE LOS GIGANTES DE LOS ANDES DE JUAN BAUTISTA ALBERDI
}

\author{
POR \\ ÉLIDA LOIS \\ Universidad Nacional de San Martín
}

Desgraciados los pueblos que necesitan héroes.

Bertolt Brecht (Galileo Galilei)

La problemática teXTUAl de los EsCRitos póstumos y el ArChivo Alberdi

Los Gigantes de los Andes -una parodia de las mitificaciones historiográficas donde Alberdi satiriza la utilización de la Historia como arma en la lucha por el poder político del presente- no ha despertado nunca la atención de la crítica. Fue publicada en los Escritos póstumos (XII, 481-569), lo que equivale a decir que se trata de un "texto problemático".

La mayor parte de las libretas y de los legajos del Archivo Alberdi ${ }^{1}$ contienen los borradores que sirvieron de base para preparar esa edición póstuma: dieciséis tomos que duplicaron en volumen la obra impresa en vida del autor y que se dieron a conocer entre 1895 y 1901; pero que contienen, también, páginas jamás publicadas. Inhallables desde hace más de cinco décadas, los Escritos póstumos fueron reeditados en 2003 por la Universidad Nacional de Quilmes; no obstante, se trata de una reedición de la primera publicación, ya que sus textos no fueron cotejados con los manuscritos ni se incorporaron los trabajos que aún permanecen inéditos.

El mismo Alberdi calificó esos manuscritos como "borradores" en su testamento de 1881: "son simples materiales para componer libros más bien que libros ya compuestos" (Córdoba 40). Pero, al no contar con originales “autorizados” por el autor, los responsables de la primera edición se empeñaron en editar borradores y anotaciones como si fueran “textos acabados” y, en busca de una cohesión y una coherencia impropia de la escritura en proceso, los reordenaron con criterios discutibles: modificaron su secuencia temporal y reagruparon parágrafos en capítulos para los que crearon títulos. Asimismo, al

1 Esta documentación se encuentra en la Biblioteca Furt (Estancia "Los Talas” de Luján, provincia de Buenos Aires), patrocinada por la Universidad Nacional de San Martín. 
alterar la progresión del discurso y su marco paratextual, se tergiversó muchas veces el pensamiento del autor: a veces, las rectificaciones se leen como contradicciones, y otras veces, se desdibujan los conflictos. ${ }^{2}$

Alberdi escribía y reescribía incesantemente, y si en el dossier genético más completo que se conserva -el De la anarquía y sus dos causas principales-, ${ }^{3}$ reformula febrilmente para exponer sucintamente ideas que venía machacando en borradores y en publicaciones diversas, en las obras que le requirieron una especial reelaboración conceptual o discursiva el volumen pre-textual tuvo que haber sido mucho mayor: es lo que debe de haber sucedido en el caso del proceso de gestación de Los Gigantes de los Andes.

Después de que, durante el período rosista, el exilio lo llevara a radicarse primero en Montevideo y después en Valparaíso, pasó de allí directamente a Europa en 1855 como Ministro Plenipotenciario de la Confederación Argentina ante las Cortes Europeas. Y como después de la batalla de Pavón -que transformó a Buenos Aires en la provincia hegemónica-, se mantuvo autoexiliado en París hasta 1879, vivió alejado de su país cuarenta y cuatro de sus setenta y cuatro años de vida. Por eso hace tiempo que los estudiosos se preguntan cómo pudo este estadista-escritor analizar con notable agudeza una problemática nacional observándola a la distancia durante más de cuarenta años; y también sobre este punto nos acerca respuestas el archivo documental conservado en la Biblioteca Furt. En el epistolario, Alberdi dialoga con voces diferentes y comenta o debate con ellas las informaciones periodísticas, documentales y bibliográficas que recibe, ${ }^{4}$ ya que a menudo las cartas iban acompañadas de recortes periodísticos o escritos de terceros; particularmente, una voluminosa y prolija carpeta de recortes de diarios de Europa y Sudamérica aporta datos sobre su documentación acerca de la vida política y cultural de dos continentes.

Como resulta indubitable que la dinámica creativa de Los Gigantes de los Andes interactúa con los borradores de Belgrano y sus historiadores -un proceso escritural paralelo-, importa destacar que la reconstrucción de esa dinámica no puede soslayar el enclave textual contiguo. El hecho de encarar el análisis de procesos de escritura en el interior de un nutrido archivo documental (que excede en amplitud las dimensiones del dossier genético stricto sensu) permite aportar datos desconocidos, no sólo con respecto a cada una de las obras estudiadas sino con respecto a la red intertextual de la que esas

2 Lamentablemente, no se conserva la totalidad de los manuscritos utilizados para preparar los Escritos póstumos; pero la reconstrucción del proceso escritural de aproximadamente la mitad de esa producción aporta indicios suficientes para encarar la relectura del resto de los textos imperfectamente editados.

3 Ver Lois, El crimen de la guerra 32-33, 271-82.

4 Vivía pendiente de las publicaciones que salían en el Plata y solicitando su envío. Así, por ejemplo, cuando se publica la tercera edición de la Historia de Belgrano, de Mitre, Gregorio Benites ya da por descontado que Alberdi la tiene en sus manos en una carta escrita en septiembre de 1876 (Lois y Pagliai II, 476).

Revista Iberoamericana, Vol. LXXX, Núm. 246, Enero-Marzo 2014, $49-65$
ISSN 0034-9631 (Impreso) 
obras forman parte y con respecto al contexto de situación en el que se insertan. Además, sugestivamente, como introducirse en un archivo equivale a entrar en un mundo de senderos que tanto se bifurcan y se entrecruzan como quedan truncos, nuestro estudio quedó inmerso en un juego de cajas chinas: el proceso escritural analizado se reveló inserto en un análisis genético emprendido por el propio autor estudiado.

\section{La génesis editorial de la obra: Historia de Belgrano de Mitre como interteXto}

En una dimensión universal, el análisis de génesis textual se había venido practicando toda vez que un lector crítico advertía la existencia de reescrituras del autor en dos o más versiones (manuscritas o editadas) de un texto y leía en esas reformulaciones significados dignos de ser tomados en cuenta. Y curiosamente, Alberdi fue un precursor inesperado de los estudios geneticistas en Hispanoamérica cuando en 1853, en medio de una famosa polémica con Domingo Faustino Sarmiento, ${ }^{5}$ analizó la génesis textual édita de una de las obras de su contrincante: Facundo o Civilización y Barbarie. Alberdi señaló que la primera edición de Facundo no era solamente la historia de la barbarie y una denuncia de los desmanes de los caudillos argentinos, sino también la historia de los errores de la civilización, representada por el elitismo del partido unitario; pero en la segunda edición, por consejo de Valentín Alsina (el antiguo líder unitario que se aprestaba a retornar al poder), Sarmiento suprimió tanto una introducción en la que reconocía que el caudillaje seguía siendo la expresión normal de la sociedad argentina, como los dos últimos capítulos, en los que se demostraba que el liberalismo desprovisto de sentido práctico estaba destinado al fracaso. Así, en esta denuncia de un acto de camaleonismo político, Alberdi captó el sentido de un proceso de génesis textual. ${ }^{6}$

En esa línea, sometió a una mirada geneticista las sucesivas ediciones de la Biografía de Belgrano de Bartolomé Mitre -siempre reformulada, retitulada y ampliada-, y el análisis de la evolución del discurso historiográfico de su enconado adversario (conocido póstumamente con el título de Belgrano y sus historiadores $)^{7}$ acompañó la lectura de las versiones publicadas en 1857 (Biografía del General Belgrano), 1859 (Historia de Belgrano) y 1876 (Historia de Belgrano y la Independencia Argentina). ${ }^{8}$ Pero una vez más, el texto que conocemos, publicado en los Escritos póstumos (y esta vez sin disponibilidad de los manuscritos sobre los cuales se estableció), ubica caprichosamente

5 Las llamadas Cartas Quillotanas (Cartas sobre la prensa y la política militante en la República Argentina, publicadas por Alberdi en 1853) fueron respondidas ese mismo año por Sarmiento en Las ciento y una; en Hispanoamérica, esa polémica marca un momento auténticamente memorable de la literatura política del siglo XIX.

6 Alberdi, Obras completas IV, 57.

7 Alberdi, Escritos póstumos V, 5-270.

8 La cuarta, y definitiva, fue publicada en 1887, después de la muerte de Alberdi.

$\begin{array}{llllll}\text { Revista Iberoamericana, Vol. LXXX, Núm. 246, Enero-Marzo 2014, } & \text { 49-65 } \\ \text { ISSN 0034-9631 (Impreso) } & \text { ISSN 2154-4794 (Electrónico) }\end{array}$ 
segmentos referidos a diferentes momentos de ese proceso editorial que se conectan con el universo del discurso de Los Gigantes de los Andes.

En lo que se publica como "Prefacio", Alberdi se sitúa durante la lectura de la segunda edición cuando declara que el biógrafo retorna a los planteamientos de la primera y examina conceptos de la "Introducción" que ha sido agregada: particularmente, critica la identificación del quehacer historiográfico con el “culto de los próceres”. Sin embargo, en esa sección se entremezclan comentarios vinculados a su análisis de la tercera edición: "Su Campaña al Paraguay es el propósito de su publicación”(pág.). Un poco más adelante, se anotan juicios que tienen que haberse escrito durante la presidencia de Mitre (1862-1868): se juzga que un presidente historiador es un presidente irresponsable, cuyo estudio "no es otro que el del gobierno mismo que está encargado de constituir y organizar" y se afirma que "pretende que lleva hoy al Paraguay la misión que llevó al general Belgrano a ese país en 1810” (31-36). Por otra parte, el epígrafe que se lee en el capítulo XI podría haber encabezado todo el ensayo:

Los escritores que escriben en los siglos aristocráticos hacen depender de ordinario todos los acontecimientos de la voluntad particular y del humor de ciertos hombres y ligan a los menores incidentes las revoluciones más importantes.

Los historiadores que escriben en los siglos democráticos no atribuyen casi ninguna influencia al individuo sobre el destino de la especie, ni a los ciudadanos sobre la suerte del pueblo. Dan, al contrario, grandes causas generales a todos los hechos más particulares. (Tocqueville, $1^{\text {a }}$ Parte, Cap. XX)

La crítica a una concepción de la historia basada en el "culto del héroe” puede aplicarse a toda la producción historiográfica mitrista y a la de otros autores contemporáneos y posteriores. La vida política estaba dominada por los “choques” entre notables; por eso, al margen de las cuestiones de fondo que tenían que ver con la organización general del Estado nacional o con las políticas públicas de largo alcance, eran los actos personales de esos notables una de las principales materias de controversia (Myers 315).

El otro eje de la censura alberdiana es la utilización política de la producción historiográfica, particularmente, la intención de derramar sobre el historiador méritos del biografiado: "Mitre se ha parado sobre la estatua de Belgrano para hacerse visible" (25). El último capítulo del ensayo destaca que la Historia de Belgrano concluye en 1816 a pesar de que el biografiado murió en 1820 (ubicándose en la lectura de la segunda edición), pero a lo largo del texto publicado se reitera una crítica que sólo pudo redactarse después de haber leído la tercera (que se extiende hasta 1821). La tercera edición incluye una amplificación de la sección dedicada a la campaña que Belgrano emprendió en el Paraguay después de la Revolución de 1810, y esa sección da pie a Alberdi para acusar a Mitre de emprender una operación subrepticia: disminuir los méritos del biografiado al disfrazar con falsa objetividad sus críticas por la ausencia de

Revista Iberoamericana, Vol. LXXX, Núm. 246, Enero-Marzo 2014, $49-65$
ISSN 0034-9631 (Impreso) 
éxito militar y enaltecer por contraste su propia capacidad en la Guerra del Paraguay. Así, un fracaso militar que sin embargo sembró ideas (Paraguay se independizó un año después de la campaña de Belgrano) es humillado por el éxito de la Guerra de la Triple Alianza en la que Mitre comandó las tropas argentinas, una empresa larga y costosa para el país que reportó más penurias que conveniencias: "Entre un general que siembra beneficios para cosechar dolores y otro que siembra perjuicios para cosechar goces, el lector educado puede llegar a elegir al segundo" (25).

Por otra parte, desde la publicación de la Galería de celebridades argentinas. Biografía de los personajes más notables (1857), que incluía entre otras colaboraciones la primera versión de la Historia de Belgrano de Mitre, Alberdi venía refiriéndose tangencialmente en diversos ensayos y en su correspondencia epistolar al tema del uso político de las mitificaciones historiográficas. Así, la dinámica escritural de Los Gigantes de los Andes se vincula también con la producción de otros textos ensayísticos publicados en los Escritos póstumos: Del gobierno en Sud-América según las miras de su revolución fundamental (¿1867?), ${ }^{9}$ La guerra o el cesarismo en el Nuevo Mundo $(1869)^{10}$ y Facundo y su biógrafo (¿1874?). ${ }^{11}$ Además, Alberdi sabía que Mitre había recibido durante 1869 el archivo documental de José de San Martín (que le fue enviado por su yerno, Mariano Balcarce) y estaba escribiendo otra vez la biografía de un prócer.

En el transcurso de un proceso escritural interrumpido y retomado a lo largo de casi dos décadas, a fines de 1874 (antes de que Mitre comenzara a difundir su Historia de San Martín y antes de que publicase la tercera edición de la de Belgrano), Alberdi sintió la necesidad de decir lo mismo de otro modo y tradujo su ensayística en clave de ficcionalización paródica: Los Gigantes de los Andes fue el resultado de esa decisión.

Los testimonios de gÉNEsis escritural de Los GigAntes DE LOS ANDES

El dossier genético no es copioso. Una última versión, inconclusa, ocupa tres libretas y se leen en hojas sueltas fragmentos de pre-textos pertenecientes a diferentes etapas escriturales: una textualización primigenia, un plan de redacción de un nuevo borrador -que no se conserva- y un parágrafo de estatuto genético incierto, ${ }^{12}$ en el cual -una vez finalizado el debate de los gigantes acerca de la organización política de las tierras independizadas- se registra una recapitulación reflexiva que podría ser un borrador encaminado a dar final a la versión redactada en las libretas. Se conservan, también, anotaciones documentales.

9 Alberdi, Escritos póstumos IV, 5-673.

10 Alberdi, Escritos póstumos II, 206-31.

11 Alberdi, Escritos póstumos V, 273-83.

${ }^{12}$ No es un borrador primigenio y está escrito en hojas sueltas de otro tipo de papel.

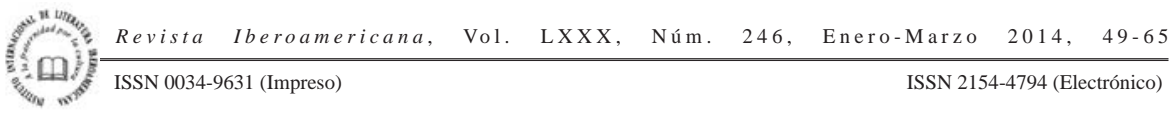


La textualización primigenia consta de cuatro apartados de una primera versión y exhibe todas las características de los borradores iniciales conservados en el Archivo Alberdi: ductus apresurado y nervioso que tanto acumula síncopas como duplica trazos u omite algún vocablo exigido por la ilación, con secuencias de transcripción dudosa o lisa y llanamente ilegibles, y con la sintaxis laxa y desmañada propia de los ensayos de escritura; por añadidura, antes bien que un relato estructurado (como el del último borrador) es una serie de esbozos narrativos.

La edición de los Escritos póstumos transcribe (con numerosas erratas, "intervenciones" sobre el texto y algunas inexactitudes) la etapa final del borrador conservado en tres libretas añadiendo numeración a sus capítulos, y suma como último apartado el texto del parágrafo suelto citado, en donde se despliega un discurso conclusivo. De todas maneras, el autor no consideraba terminado su trabajo: faltaba numerar y asignar títulos a sus apartados, ${ }^{13}$ que el manuscrito separa precediéndolos por el signo de parágrafo (§); Alberdi siempre postergaba este trabajo para el final de sus procesos textuales. Sin embargo, ya había incorporado subtítulos en los borradores primigenios conservados; así, esta ausencia es un indicio más de la magnitud de la empresa reelaboradora que desembocó en la última versión conservada. ${ }^{14}$

Alberdi utilizaba para sus cartas los típicos cuadernillos de 4 páginas (resultantes de una hoja de papel Manila ${ }^{15}$ plegada al medio), y en ellos solía registrar anotaciones repentinas. En el reverso en blanco del folio 7 del primer borrador, había comenzado a redactar una carta datada así:

Señor don J

St. André de Fontenay

26 de nov $^{\text {bre }}$ de 1874.

Que este comienzo epistolar fallido se encuentre en medio de una primera textualización de Los Gigantes de los Andes sitúa el comienzo del proceso escritural meses después del envío a imprenta de otra parodia farsesca (Peregrinación de Luz del Día o Viaje y aventuras de la Verdad en el Nuevo Mundo) y antes de haber terminado sus apuntes

${ }^{13}$ Sólo dos capítulos llevan un título: el II (“Origen de los Gigantes Sudamericanos”) y el III (“Dónde y cómo se educaron los Gigantes de los Andes”).

${ }^{14}$ Es una evidencia indirecta de esta aserción el impresionante volumen del dossier genético de un breve ensayo como De la anarquía y sus dos causas fundamentales: una lista de títulos posibles, tres planes sucesivos de la totalidad de la obra, un cuarto plan con breves esbozos de textualización, tres borradores con numerosas reescrituras, papeles sueltos con numerosos esbozos textuales de los diferentes parágrafos y dos apógrafos sucesivos (copias de un secretario) con enmiendas de puño y letra de Alberdi.

${ }_{15}$ Hasta comienzos del siglo xx esta denominación individualizaba un tipo de papel delgado de color beige, empleado corrientemente en la correspondencia epistolar, en tanto que en la actualidad, se identifica así un papel más grueso utilizado en bolsas y sobres.

ISSN 0034-9631 (Impreso) 
acerca de Belgrano y sus historiadores (después de conocer la tercera edición de la Historia de Belgrano de Mitre).

La última versión registrada en los manuscritos conservados llevaba el título NOTAS para servir de introducción a la historia y a la literatura de la América del Sud ${ }^{16}$ una denominación que destaca su condición de borradores. Pero sobre la marcha escritural que se lee en la primera libreta, Alberdi decidió un título para la obra y lo escribió (y reescribió) en la guarda de tapa (donde solía inscribir modificaciones paratextuales): LOS GIGANTES DE LOS ANDES, o sea, De la reconstrucción moderna de la América del Sud, según su historia tradicional y popular (título que encabeza las restantes libretas). Probablemente en una etapa ulterior, comenzó a copiar después de ese título el borrador de un "Prefacio", que continuó transcribiendo en el dorso en blanco de las páginas siguientes; de acuerdo con la metodología escrituraria de Alberdi, esas palabras preliminares habrían sido precedidas por una primera redacción en hojas sueltas, pero la numeración de los items revela que el autor está enhebrando conceptos sueltos que tiene la intención de compaginar.

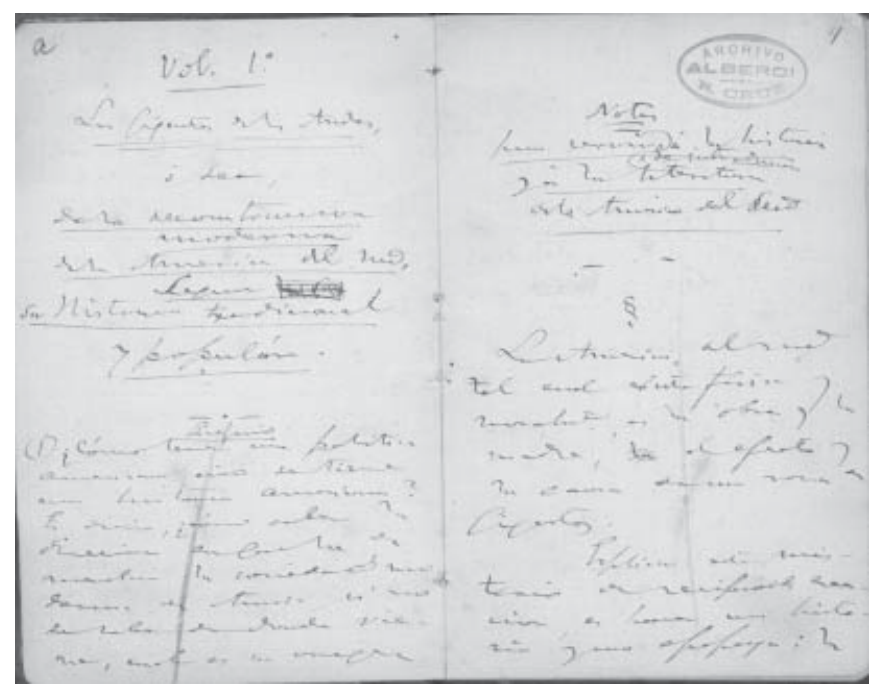

Ilustr. 1. En la guarda de tapa de esta libreta (donde la abreviatura "Vol. 1" " indica que se trata de la primera de las tres libretas conservadas), Alberdi agregó un primer

${ }^{16}$ En las obras de Alberdi publicadas en vida, se transcriben con mayúsculas los vocablos que llevan doble subrayado en los manuscritos.

Revista Iberoamericana, Vol. LXXX, Núm. 246, Enero-Marzo 2014,
ISSN 0034-9631 (Impreso) 
título: los gigANTES DE LOS ANDES, o sea, De la reconstrucción de la América del Sud. Historia tradicional y popular. Pero en una reescritura posterior, intercaló el adjetivo “moderna” y decidió una reformulación sintáctica que permitió reducir la opción a dos frases ("según su historia tradicional y popular”).

No es inusual que un autor recupere en sus prólogos, total o parcialmente, las intenciones que lo impulsaron a escribir: Los gigantes de los Andes es un texto generado a partir de reflexiones metahistóricas. El primer ítem del "Prefacio" retoma el planteo que había explicitado en 1837 en el discurso que pronunció en la inauguración del Salón Literario: “en una sociedad, saber de dónde venimos es saber adónde vamos”:

(I) ¿Cómo tener una política americana, si no se tiene una historia americana? Es decir, ¿cómo saber la dirección en que ha de marchar la sociedad moderna de América, si no se sabe de dónde viene, cuál es su origen moderno?

Proyecta luego el rechazo que le producen las ficcionalizaciones encaminadas a obtener réditos políticos por medio del impacto emocional (el mismo desagrado que, en $\mathrm{El}$ crimen de la guerra, lo impulsa a condenar la poesía épica por su incidencia en la exacerbación del belicismo):

(II) Pero, ¿cómo tener una historia de los hechos, de los hombres, de las cosas de América, cuando no se desea ni se busca otra cosa que cuentos y novelas de esos hechos, cosas y personas?

Y el "Prefacio" conservado concluye con una síntesis de su concepción del modo de encarar las reconstrucciones históricas:

(VIII) Para ver la realidad es preciso salir de la fábula.

(IX) Es tiempo de estudiar la historia como ciencia, no como literatura y poesía, según se ha tomado hasta aquí por los que explican un origen como sobrenatural y sobrehumano. Estudiarla en los hechos que forman su realidad, no en las ficciones, fábulas y mitos formados sobre esos hechos para la imaginación, para que solo vivan en la imaginación.

Sin duda este proceso escritural se asocia a las reflexiones que le suscita la historiografía argentina contemporánea, pero la primera textualización conservada arranca de un desborde emocional que elige el cauce de la parodia farsesca, de allí que esta vez no se encamine por la senda de Tocqueville ni la del historicismo romántico: su fuente es el Gargantua de François Rabelais. ${ }^{17} \mathrm{Y}$ el Dr. Alberdi -que ya ha instalado una imagen de

${ }^{17}$ Las obras de Rabelais estaban en la biblioteca de Alberdi (Mayer 924), pero el último borrador contiene una mención explícita de esta conexión.

Revista Iberoamericana, Vol. LXXX, Núm. 246,
ISSN 0034-9631 (Impreso) 
legislador e intérprete de la realidad y la cultura sudamericana-abandona tanto la voz del tratadista enjundioso como la del polemista político (que se entrecruzan constantemente en su última ensayística) para inscribirse en la tradición "carnavalesca”. Así, da una vuelta de tuerca a otra sección de su obra, que había pasado por la sátira de costumbres de Figarillo y la farsa de El gigante Amapolas para acabar desembocando recientemente en esa parodia amarga de la vida política del Plata que es Peregrinación de luz del día.

El último borrador individualiza desde el capítulo inicial a cuatro gigantes nacidos de un cataclismo de la Madre Tierra que les permite brotar de picos y volcanes de gran altura en la cordillera de Los Andes: Simundo (Simón Bolívar), San Martillo (José de San Martín), Orígenes (Bernardo O’Higgins) y Belgrande (Manuel Belgrano). El dueño de ese territorio era entonces un gigante de allende el Atlántico que los envió a cursar estudios con gigantes europeos; pero el gigante español más tarde se vio vencido por el gigante de las Galias y, en ese contexto, ellos regresan a tomar posesión de su tierra natal.

El borrador primigenio, una narración que en general habla del conjunto de los gigantes sin marcar rasgos individuales, comienza por "El desembarco" (título del primer capítulo conservado): el arribo a Sudamérica de seres de tamaño tan descomunal que no pueden ser distinguidos por los hombres corrientes, que los confunden con montañas. Y en el segundo apartado (que no lleva título), el narrador comenta cómo esa enorme desproporción motiva la incapacidad para comprender la naturaleza de las acciones emprendidas por ellos.

El tercer capítulo (“Acciones y proezas guerreras de los Gigantes”) está incompleto y sólo se leen las hazañas rabelaisianas de San Martillo y de Orígenes en la sección sur de la cordillera. Las andanzas de San Martillo, por ejemplo, emulan las de Gargantua:

Se mantenía oculto en cuclillas en un valle: el ejército español campaba en el monte vecino. Al amanecer $\mathrm{S}^{\mathrm{t}}$ Martino se paraba de un golpe y su mero aspecto hacía eseapar fugar despavoridos a todos los soldados enemigos, que temían ser devorados por la boca abierta de aquel Gigante que los de un diámetro de media cuadra.

Otras veces se ocultaba detrás de un cerro encumbrado de los Andes, al pie del cual campaba el ejército español. Por la noche el Gigante hacía pis en lo alto de la montaña, y media hora después perecía inundado y ahogado todo el ejército español.

De un pedo hacía naufragar un navío de vela español.

Del otro lado de la cordillera, Orígenes emula sus proezas y ambos departen sin necesidad de tener que cruzar el macizo montañoso:

En el verano, apoyadosen apoyando sus codos en sus cumbres, tomaban mate y fumaban largas horas [hablando] sobre cosas de la guerra.

Revista Iberoamericana, Vol. LXXX, Núm. 246, Enero-Marzo 2014, $49-65$
ISSN 0034-9631 (Impreso) 


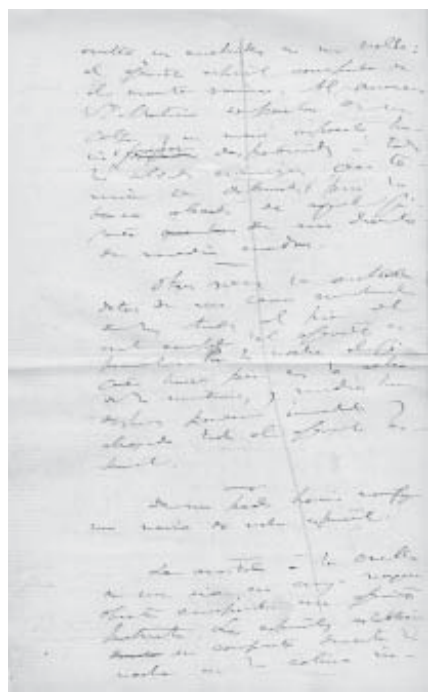

Ilustr. 2. La primitiva textualización (en donde la denominación "San Martillo" alterna con "San Martino") apunta imágenes rabelaisianas destinadas a narrar las hazañas de los gigantes.

El último capítulo de esta serie ("Reformas y cambios ulteriores a la guerra”) discurre acerca de las transformaciones políticas y sociales que siguieron a las guerras de independencia presentándolas como el resultado de una planificación de los cuatro gigantes, enfocados otra vez como un conjunto homogéneo. Tal como había sostenido en La guerra o el cesarismo en el Nuevo Mundo, Alberdi denuncia lo que considera el pecado original de la política postindependentista: la transformación de los guerreros en caudillos políticos cuyo autoritarismo, reproduciendo el sistema de mandos de la vida militar, impide la instalación de una auténtica democracia y la consolidación de un sistema jurídico que asegure el ejercicio de las libertades individuales.

No hay dudas acerca de que "El desembarco" pertenece a una etapa exploratoria, pero no tenemos pruebas que permitan asegurar que constituye el momento exacto en que se desencadenó el proceso escritural y que no haya estado precedido de algún tipo de introducción. De todas maneras, igual resulta evidente que el diseño estructural que transcribimos a continuación antecede la redacción de un nuevo borrador, ya que si bien los cuatro ítems que encabezan la segunda sección se corresponden con los cuatro parágrafos del borrador primigenio, la reescritura de los títulos del primer apartado y del tercero, la intercalación de un título para el segundo (que no lo llevaba) y la amplificación del cuarto (que pasa a encararse subdividido en cuatro ítems) son marcas de la iniciación de otra campaña de escritura:

Revista Iberoamericana, Vol. LXXX, Núm. 246,
ISSN 0034-9631 (Impreso) 
PLAN

$\S$

- Crear la sociedad civil americana

- Cómo? por qué método?

- Seguir discusión en lo que puede ser llamado un Congreso Americano preparatorio de la independencia.

- Cuestiones de límites, puertos y rentas en el pacto que hará el Congreso del Penedo de San Pablo. Equilibrio Sud-Americano.

- Actitud para el Brasil, constituido como el Portugal [? $]^{18}$ en Europa, entre el Atlántico y el pueblo que habla español.

- Jaque perpetuo de la raza española. $\S$

- El desembarco en América.

- Nadie ve a los Gigantes a fuerza de ser grandes.

- La campaña y sus prodigiosas hazañas, según los historiadores y la tradición de Sud América.

- Resultados de la guerra victoriosa.

- Refundación, cambios, reconstrucción, por los Gigantes, del mundo americano; de su suelo, geografía, habitantes, animales, plantas, montañas, ríos, campos.

- Abolir todo lo que en este orden hubiera introducido y formado la conquista española.

- Renovado todo o rehecho ${ }^{19}$ todo americano por un decreto -las fuentes, los animales, los hombres \&\&. ${ }^{20}$

Este bosquejo escritural de Alberdi separa dos secciones: la primera, anterior al desembarco que da principio al borrador primigenio, se centra en la planificación de la campaña militar y sus resultados: el reparto regional del nuevo poder y un acuerdo político general. El espacio que ocupa en este diseño estructural la temática brasileña sitúa su redacción en cercanía con la fecha de inicio del proceso escritural. Todavía no ha pasado demasiado tiempo desde la publicación de El Imperio del Brasil ante las democracias de América, la compilación de todos los escritos geopolíticos de Alberdi sobre la cuestión del Paraguay que precedieron y acompañaron la guerra de la Triple Alianza. Esa recapitulación de 1869 todavía está circulando ampliamente en el Plata en 1874, ya que si bien durante el transcurso de la contienda -y particularmente, en Buenos Aires- aquellos escritos habían originado la acusación de "traidor a la Patria" que amargó la vejez de Alberdi, después de las penurias resultantes y de los bochornosos tratados que firmó el barón de Cotegipe con el país vencido en perjuicio de Argentina (1872), las acusaciones de traición se fueron trocando en consideración y respeto.

${ }_{18}^{18}$ Dos o tres grafemas ilegibles, tachados.

19 Aquí, o después del vocablo siguiente (“todo”), falta una coma.

20 Antigua abreviatura de "etcétera".

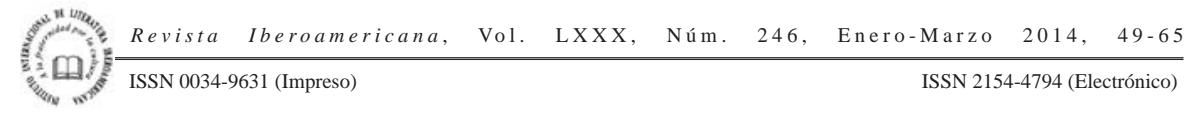


No obstante, en el último borrador, sólo resta de ese temario la ubicación geográfica del lugar donde transcurre el debate de los gigantes a su regreso de Europa y antes de pisar el suelo hispanoamericano (el Penedo de San Pablo) ${ }^{21}$ y un comentario fugaz en el comienzo del sexto parágrafo: el Portugal americano (a la vista de los gigantes desde allí) será siempre un punto de referencia ineludible a la hora de considerar la política de Hispanoamérica.

La salida de foco de esa temática motiva la reestructuración total del único plan conservado: en el último borrador, los dos períodos históricos se tratan en el Congreso del Penedo de San Pablo. Después de una narración introductoria que insume seis apartados, ocupa los catorce siguientes el debate de los Gigantes -el núcleo de la obra-, donde no sólo se planifican las campañas militares por la independencia sino también el futuro político de Hispanoamérica. Con la votación de las propuestas culmina el borrador que se lee en las tres libretas.

La primera reformulación llamativa es el cambio de registro: Alberdi matiza la cuerda rabelaisiana en la que había narrado proezas militares. La crudeza del humor escatológico deviene una de esas típicas salidas truncas que suelen morir en los pre-textos (sólo queda algún ingrediente, borroneado, durante la creación del río Orinoco por parte de Simundo y del Paraná por parte de Belgrande), pero sobrevive la desmesura en la parodia del relato mitológico de los capítulos iniciales (los gigantes -que han cruzado el océano a nado- también darán origen a accidentes geográficos de las regiones que se han repartido previamente antes de emprender sus campañas militares). De todas maneras, queda una marca explícita de la conexión inicial cuando Belgrande crea una bandera para su país (un acto exaltado por la historiografía satirizada por Alberdi y el gesto al que ha quedado reducido el personaje histórico en el relato posterior de la escuela elemental argentina) y fundamenta su elección con este argumento:

-Efectivamente -dice Belgrande-, nunca los gigantes, como anfibios que son, del cielo y de la tierra, dejaron de tener como colores naturales el azul y el blanco. Puedo citar, en apoyo de esto, las palabras del Gigante Gargantua, que cuando la lengua de Francisco I estaba en pañales explica oficialmente esos colores del siguiente modo: "Les couleurs de Gargantua furent blanc et bleu”. ¿Por qué razón? Según su padre, porque "le blanc lui signifiait foie, plaisir, et le bleu, choses celestes”. (520) ${ }^{22}$

La reelaboración introduce, además, una mutación en el discurso y en la modelación actancial. En el debate, la narración es reemplazada por una dialogia en la que uno de los gigantes habla, desde el primer momento, con una voz diferente: Belgrande (la

\footnotetext{
${ }^{21}$ Antigua denominación del Archipiélago de San Pedro y San Pablo.

${ }^{22}$ Las citas del debate de los gigantes -que se corresponden con la última versión de los borradores conservados- pertenecen a la edición publicada en los Escritos póstumos.
}

ISSN 0034-9631 (Impreso) 
personificación del único de los cuatro comandantes que no era un militar por formación -como San Martín- ni por vocación -como Bolívar y O’Higgins-). Belgrano se había graduado en Derecho, se había orientado hacia el estudio de la economía política y había elaborado una programática que pudo empezar a poner en práctica ya como funcionario criollo del virreinato: su participación protagónica en la Revolución de Mayo lo obligó a desempeñarse como jefe militar.

Desde el inicio del debate, Belgrande comienza a cuestionar los objetivos y la metodología del manejo del poder. Y una vez votada la decisión de dar la libertad a América, plantea lo que considera la problemática esencial: ¿cómo dar la libertad a un pueblo que procede de España, "donde ni de nombre es conocida la libertad”? A los otros gigantes sólo les preocupa sustituir al rey de España en el gobierno: acaso, “¿puede un hombre librarse del gobierno de su propio país?”:

-La Inglaterra, sin embargo -dice Belgrande-, es un país donde cada hombre se gobierna a sí mismo.

El gigante San Martillo, al oír esto, casi muere de risa como el rey de Prusia cuando, preguntando por su rey a un embajador de Venecia, le respondió que no había rey en su república. (505)

De entrada entonces, Belgrande habla con la voz de Alberdi, que reitera en boca del personaje todos los argumentos que atraviesan su propia obra de cabo a rabo, en tanto los demás gigantes susurran críticas y se burlan a sus espaldas de lo que consideran delirantes fantasías de un graduado universitario.

La segunda cuestión es la de la elección de los instrumentos que aseguren la libertad. Y en contra de Belgrande, que sostiene que "la industria y el comercio pueden ser mejor camino que la guerra para llegar a la libertad", los demás coinciden en que "no puede haber otro instrumento que la espada, ni otro camino que la guerra”, y sobre la base de la voluntad mayoritaria se declaran los principios básicos del gobierno futuro:

-Toda nación tuvo sus gigantes; todos los gigantes fueron guerreros [...]. Seremos los fundadores de esa raza dirigente [...]. Nuestros sucesores heredarán el gobierno con nuestros nombres. (508)

Pero también declaran que no desdeñan a los colaboradores letrados y diseñan una política cultural:

-La retórica es la reina del mundo y su cetro es la frase. Con abundantes poetas, oradores y abogados, no habrá hazaña de que no seamos autores, no habrá gloria que la historia no nos adjudique, no habrá derecho que no conceda la opinión pública. (511-12)

Revista Iberoamericana, Vol. LXXX, Núm. 246, Enero-Marzo 2014, $49-65$
ISSN 0034-9631 (Impreso) 
Y cuando se pasa de inmediato a considerar la cuestión vital del sostenimiento del gobierno, la organización financiera se identifica con el "comisariato de guerra":

-La América independiente será la patria favorita de los comisarios y de las comisarías de guerra [...]; y los Gigantes de los Andes tendrán carta blanca para girar sobre las montañas de oro y plata maciza de que los Andes son la caja de fierro, perteneciente a la tesorería de un mundo. Ese oro y esa plata que por siglos alimentaron a los gigantes de España serán el alimento de los gigantes llamados a libertar la América de los españoles, en la forma en que los españoles la libertaron de los incas y de los aztecas. (530-31)

Belgrande hace un último esfuerzo persuasivo en el que reitera el programa político alberdiano encaminado a la consolidación de una "sociedad civil americana": ajuste de la acción política a la legalidad, controles para el ejercicio del poder, libertades individuales y todos los medios conducentes al progreso (educación para el trabajo y la libertad, la creación de riqueza, "intercambio con el mundo civilizado"). De todas maneras, San Martillo resume a su manera esa programática y propone la última moción que aprobará la mayoría:

-[...] Mientras el tiempo nos enseña a conocer el mejor método para educar al pueblo en el ejercicio de sus libertades, no veo inconveniente en que le demos escritas todas las libertades civiles y sociales que quiera, con tal que él nos deje a los libertadores y gobernantes toda la libertad de gobernarlo de hecho. Iremos viviendo del trabajo de ejercer esa libertad que se llama gobierno, mientras el pueblo aprende a manejar su libertad de obedecer y de mejorarse, como mejor pueda, obedeciendo. (565-66)

Así finaliza el texto de los borradores de las libretas y el capítulo conclusivo conservado en hojas sueltas termina lamentando con desesperanza las consecuencias de la instalación de “una verdadera caballería andante americana” (569).

\section{CONCEPTUALIZACIONES METAHISTÓRICAS, PARODIA Y AUTOFICCIÓN}

El universo intertextual que enmarca el proceso escritural analizado, al mismo tiempo que busca claves en la historia para interpretar la realidad política, denuncia en la historiografía contemporánea los instrumentos para deformar lo que considera una interpretación correcta. Pero mientras Alberdi intenta en la escritura ensayística atrapar la "realidad" de su país y se propone "interpretarla" (encontrar una "verdad" desde la óptica presuntamente objetiva del intelectual), en su escritura literaria impone su "verdad".

Los gigantes de los Andes entra de lleno en el género paródico articulando en una síntesis el discurso de los historiadores oficiales y su caricaturización farsesca, es decir, reitera con "distancia crítica”, pero en el producto cobran más relieve las diferencias que la identificación con el hipotexto. Los mecanismos de la parodia están muy lejos

Revista Iberoamericana, Vol. LXXX, Núm. 246, Enero-Marzo 2014, $49-65$
ISSN 0034-9631 (Impreso) 
de las burlas festivas de su juventud: pretenden crear en el lector el malestar de quien al entrar en una sala de espejos deformantes presiente que los cristales le están revelando una verdad encubierta por la máscara de las normas impuestas. El objetivo es el mismo de los ensayos, pero el procedimiento comunicativo básico ya no es argumentar sino mostrar, aunque la trama vaya tejiendo el crudo teorema social que descubre cuál es el motor de la acción política.

En el proceso textual de Los gigantes de los Andes la autoficción no gobierna la marcha del discurso desde el comienzo como en Peregrinación de luz del día, pero al decidir que el personaje de Belgrande exponga el programa alberdiano, el propio Alberdi termina introduciéndose en su mitificación historiográfica por ese camino oblicuo: un tipo de "escritura del yo" que se escapa de la autobiografía para introducirse por los intersticios de diferentes géneros discursivos y convierte realidades en ficción incorporando una estrategia de relaciones complejas entre autor real, autor implícito y narrador. Otra vez el yo de Alberdi penetra en la ficción para hablar con la voz de la Verdad -esa Luz del Día que quiere ser la forma más decantada de su conciencia crítica-, para demostrar que no está dispuesto a claudicar de ese papel analítico y programático que lo convirtió en lo más parecido a un intelectual puro que tuvo el pensamiento político argentino del siglo xix. Y justamente, esta vez, el mecanismo autoficcional lo conduce a identificarse con un personaje histórico a quien quiere desmitificar como prócer y revalorizar como intelectual.

Alberdi desmonta en su análisis de la historiografía nacional algunos de los mecanismos utilizados por el poder político para ejercer la supremacía narrativa, pero en tanto los actores denunciados viven sumergidos en el barro de la historia, el intelectual crítico no se enloda. Sin embargo, no suele estar exento de las mismas apetencias de predominio: la proyección autoficcional que convierte a Alberdi en un pensador que supera el proyecto político-económico de Belgrano se inscribe en esa línea.

Sin embargo, un autor que ha demostrado en sus papeles privados utilizar la reescritura para comprender, no teme entrar en terrenos resbaladizos con sus propias postulaciones. En el décimo parágrafo, Belgrande entra en oposición con una de las tesis alberdianas más conspicuas (que, por otra parte, acaba de ser puesta en foco en la conferencia de la Verdad con que se cierra Peregrinación de luz del día y será reiterada en trabajos posteriores): la fe ciega en la división internacional del trabajo y el librecambismo a ultranza. Belgrande propugna allí -aunque con cierta timidez y con ciertos ingredientes que lo ridiculizan-un programa concentrado en la incentivación de la industria nacional que es rechazado por los restantes gigantes con un argumento contundente: no están dispuestos a renunciar al armamento extranjero. No obstante, el pasaje no deja de ser ambiguo: ¿̇respeto por la verdad histórica (ya que Belgrano proponía un programa económico pragmático que -sin dejar de atender al mercado externo- propugnaba el desarrollo de una industria nacional)?, ¿ o una de esas esporádicas grietas que atraviesan el pensamiento ilustrado y liberal del último Alberdi?

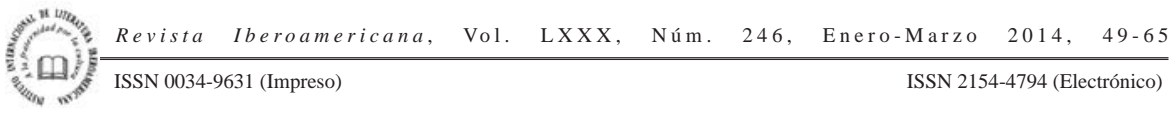


Los pre-textos multiplican las incógnitas que plantean los textos porque presentan in progress la contienda entre la palabra y el pensamiento.

\section{BiBLIOGRAFÍA}

Alberdi, Juan Bautista. Belgrano y sus historiadores. Escritos póstumos. Buenos Aires: Imprenta Europea, 1897. Tomo V. 5-270.

Cartas sobre la prensa y la política militante en la República Argentina. Valparaíso: Imprenta del Mercurio, 1853.

Escritos póstumos. Buenos Aires: Imprenta Europea, 1895-1897 (tomos I-V); Imprenta Alberto Monkes, 1898-1900 (tomos VI-XI); Imprenta Juan Bautista Alberdi, 1900-1901 (tomos XII-XVI).

Los Gigantes de los Andes. Escritos póstumos. Buenos Aires: Imprenta Juan Bautista Alberdi, 1900. Tomo XII. 481-569.

El Imperio del Brasil ante las democracias de América. París: Imprenta A. E. Rochette, 1869.

Obras completas. Buenos Aires: La Tribuna Nacional, 1886-1887. Tomos I-VIII. Peregrinación de luz del día o viajes y aventuras de la verdad en el nuevo mundo. Élida Lois, edición crítico-genética anotada, estudio preliminar y apéndice documental. San Martín: UNSAM Edita (en prensa).

Córdoba, Alberto Octavio. Los escritos póstumos de Alberdi. Buenos Aires: Ediciones Teoría, 1966.

Gasparini, Philippe. Autofiction. Une aventure du language. Paris: Seuil, 2008.

Lois, Élida. "Estudio preliminar". Edición crítico genética de La guerra o el cesarismo en el Nuevo Mundo de J. B. Alberdi. San Martín: UNSAM Edita, 2005. 5-34.

Edición crítico-genética, "Estudio preliminar" y "Apéndice documental”. El crimen de la guerra. Juan Bautista Alberdi. San Martín: UNSAM Edita, 2008. 13-63, 265-91.

Lois, Élida y Lucila Pagliai, ed. Epistolario inédito (1864-1883) de Juan Bautista Alberdi y Gregorio Benites. Asunción del Paraguay: Fondec, 2007. Tomos I-III.

Mayer, Jorge M. Alberdi y su tiempo. Buenos Aires: EUDEBA, 1963.

Mitre, Bartolomé. Historia de Belgrano. Buenos Aires: Imprenta de Mayo, 1859. Historia de Belgrano y de la Independencia Argentina. Buenos Aires: Imprenta de Mayo, 1876.

Morón Usandivaras, Mariana. "El taller de escritura de Alberdi. La génesis de un pensamiento”. Recto / Verso. Revue de jeunes chercheurs en critique génétique 5 (2009). Web. < http://revuerectoverso.com:80>.

Myers, Jorge. "Aquí nadie vive de las Bellas Letras. Literatura e ideas desde el Salón Literario a la Organización Nacional”. Historia crítica de la literatura argentina. Noé

Revista Iberoamericana, Vol. LXXX, Núm. 246, Enero-Marzo 2014, $49-65$
ISSN 0034-9631 (Impreso) 
Jitrik, director. Tomo II. La lucha de los lenguajes. Julio Schvartzman, coordinador. Buenos Aires: Emecé Editores, 2003. 305-33.

Rodríguez, Ricardo. Catálogo analítico del Archivo epistolar de Juan Bautista Alberdi. San Martín: Escuela de Humanidades, UNSAM, 2004 (CD-Rom).

Sarmiento, Domingo Faustino, Bartolomé Mitre, Juan María Gutiérrez, Félix Frías et alii. Galería de Celebridades Argentinas. Biografía de los personajes más notables. Buenos Ayres: Ledoux y Vignal editores, 1857-1858.

Sarmiento, Domingo Faustino. Civilizacion i barbarie. Vida de Facundo Quiroga, i aspecto físico, costumbres i hábitos de la República Argentina. Santiago de Chile: Imprenta del Progreso, 1845.

Civilizacion i barbarie. Vida de Facundo Quiroga, i aspecto físico, costumbres i hábitos de la República Argentina. $2^{\mathrm{a}}$ edición. Santiago de Chile: Imprenta de J. Belin i Compañía, 1851.

Las ciento y una. Santiago de Chile: Imprenta de J. Belin i Compañía, 1853.

Wasserman, Fabio. Entre Clío y la Polis. Buenos Aires: Teseo, 2008.

Revista Iberoamericana, Vol. LXXX, Núm. 246, Enero-Marzo 2014,
ISSN 0034-9631 (Impreso) 
